\title{
Early-occurring proliferation defects in peripheral tissues of the Ts65Dn mouse model of Down syndrome are associated with patched1 over expression
}

\author{
Claudia Fuchs, Elisabetta Ciani, Sandra Guidi, Stefania Trazzi and Renata Bartesaghi
}

Down syndrome (DS) is a genetic pathology due to the triplication of human chromosome 21. In addition to mental retardation, individuals with DS exhibit a large range of variable traits, including co-occurring congenital malformations. It is now clear that neurogenesis impairment underlies the typically reduced brain size and, hence, mental retardation in individuals with DS. The small body size and the constellation of congenital malformations in children with DS suggest that proliferation defects may involve peripheral tissues, in addition to the brain. The goal of the current study was to establish whether a generalized impairment of cell proliferation is a key feature of the trisomic condition. We used the Ts65Dn mouse, a widely used DS model, and examined proliferation in tissues with different embryological origin by 5-bromo-2-deoxyuridine immunohistochemistry. We found that 2-day-old (P2) Ts65Dn mice had notably fewer proliferating cells in the heart and liver, and in all proliferating niches of the skin and intestine. A reduced proliferation rate was still present in the intestine at P15. In all tissues, Ts65Dn mice had a similar number of apoptotic cells as euploid mice, indicating no unbalance in cell death. In the skin, liver and intestine of trisomic mice, we found a higher expression of patched1 (Ptch1), a receptor that represses the mitogenic sonic hedgehog (Shh) pathway. This suggests that Ptch1-dependent inhibition of Shh signaling may underlie proliferation impairment in trisomic peripheral tissues. In agreement with the widespread reduction in proliferation, neonate trisomic mice had a reduced body weight and this defect was still present at 30 days of age. Our findings show that, in all examined peripheral tissues, Ts65Dn mice exhibit a notable reduction in proliferation rate, suggesting that proliferation impairment may be a generalized defect of trisomic precursor cells.

Laboratory Investigation (2012) 92, 1648-1660; doi:10.1038/labinvest.2012.117; published online 13 August 2012

KEYWORDS: APP; Down syndrome; proliferation; Ptch1; Shh signaling; somatic development

Down syndrome (DS), a genetic pathology due to a triplication of human chromosome 21 , is the most common autosomal aneuploidy compatible with postnatal survival, occurring in 1 out of $700-1000$ live births. ${ }^{1}$ Mental retardation, starting from birth and worsening with age, is the most invalidating feature of all DS cases, with a large impact on public health. The DS brain is characteristically small, and accumulating evidence in human fetuses with DS and DS mouse models clearly shows that this defect is due to widespread neurogenesis impairment that can be traced back to very early developmental stages. $^{2-7}$ Consequently, neurogenesis defects leading to brain hypocellularity appear to be a major determinant of cognitive disability in DS.

In addition to cognitive impairment, individuals with DS exhibit a large range of variable traits, including co-occurring congenital malformations that require surgical and medical management. ${ }^{8-10}$ Overall, about one in five children with DS die before the age of 5 years, and about two out of five survivors have major health problems in addition to mental retardation in early childhood. ${ }^{10}$ Congenital heart diseases are the most frequently documented birth defects in infants with DS and approximately $46 \%$ are born with one or more heart defects that include atrioventricular canal defects, ventricular septal defects and patent ductus ateriousus. ${ }^{9}$ The next most common malformations in children with DS are those of the gastrointestinal tract, such as duodenal atresia, Hirschsprung's disease and tracheo-oesphaegal fistula. ${ }^{10}$ DS is also associated with other medical problems such as opthalmological and hearing problems, dental problems, atlantoaxial sublocation, and dermatological disorders. ${ }^{9,11}$

Department of Human and General Physiology, University of Bologna, Bologna, Italy

Correspondence: Professor R Bartesaghi, MS, Dipartimento di Fisiologia Umana e Generale, Piazza di Porta San Donato 2, I-40126 Bologna, Italy.

E-mail: renata.bartesaghi@unibo.it

Received 14 May 2012; revised 11 July 2012; accepted 12 July 2012 
Hypothyroidism and obesity are also common features in DS. Initially, children with DS are underweight for their height but become overweight with age, probably due to a reduced resting metabolic rate. ${ }^{12}$

The small body size at early life stages and the constellation of congenital somatic defects in individuals with DS suggest that the proliferation defects present in the central nervous system may also involve peripheral tissues. Although most experimental studies on DS have been focused on alterations of brain development, there are very few studies that have examined peripheral tissues. An intriguing possibility is that proliferation in other tissues, apart from the brain, could also be impaired and that this defect may underlie the delayed growth, congenital defects and medical problems of children with DS. Neural precursor cells from the subventricular zone (SVZ) of Ts65Dn mice exhibit a higher expression of the sonic hedgehog (Shh) receptor patched 1 (Ptch1). ${ }^{13}$ Ptch1 exerts a negative effect on the membrane receptor smoothened (Smo). Smo is responsible for activating the downstream element of the Shh pathway, thereby stimulating cell proliferation. As repression of Smo by Ptch1 reduces cell proliferation, the increased expression of Ptch1 in trisomic precursors accounts for their reduced proliferation rate. Our group has previously shown that the increased expression of Ptch1 in neural precursors of trisomic mice is due to an excessive formation of amyloid precursor protein intracellular domain, a soluble fragment of amyloid precursor protein (APP). ${ }^{13}$ As APP is a trisomic gene, its over expression may also cause an increased expression of Ptch1 in peripheral tissues, which, in turn, may reduce proliferation potency.

In a previous study, ${ }^{14}$ we found that cultured fibroblasts from trisomic mice exhibited a reduced growth due to a decreased proliferative lifespan and premature entry in a senescence-like state, with no changes in cell cycle length. The possibility exists that the culture condition, necessarily different from a natural environment, may enhance the process of early senescence that is characteristic of DS, ${ }^{15-17}$ thereby preventing detection of proliferation deficits due to cell cycle alterations. In the current study, we were interested in establishing whether impairment of cell proliferation due to mitogenic signaling defects is a generalized feature of the trisomic condition and whether Ptch1 over expression is a common denominator for cell proliferation impairment in DS. As in the in vivo condition cells are growing in their natural environment, we examined the effect of trisomy in vivo, in different peripheral tissues. We examined cell proliferation in neonate euploid and Ts65Dn mice, taking advantage of the fact that mice are very immature at birth and, therefore, a substantial proliferation still takes place in numerous tissues. The demonstration of a reduced proliferation during early life stages in a DS mouse model could be a first approach to providing an explanation to the causes of various birth defects and malformations found in DS subjects.

\section{MATERIALS AND METHODS}

\section{Ts65Dn Mouse Colony}

Female Ts65Dn mice carrying a partial trisomy of chromosome $16^{18,19}$ were obtained from Jackson Laboratories (Bar Harbour, ME, USA) and maintained on the original genetic background by mating them to C57BL/6JEi $\times$ C3SnHeSnJ (B6EiC3) F1 males. All animals were karyotyped by real-time quantitative PCR (qPCR) as previously described. ${ }^{20}$ The mean number of offspring was 6 (range: $4-8$ ) per litter and about $25-30 \%$ of them exhibited partial trisomy of chromosome 16. The remaining animals were euploid, and not trisomic, and were used as control mice. The day of birth was designed as postnatal (P) day zero and animals with $24 \mathrm{~h}$ of age were considered as 1-day-old animals (P1). The animal's health and comfort were veterinary controlled. The animals had access to water and food ad libitum and lived in a room with a 12:12-h dark:light cycle. Experiments were performed in accordance with the Italian and European Community law for the use of experimental animals and were approved by the Bologna University Bioethical Committee. In this study, all effort was made to minimize animal suffering and to keep a minimum numbers of animals used.

\section{Experimental Protocol}

Animals of postnatal ages P2 $(n=6$ euploid mice and $n=5$ Ts65Dn mice) and P15 ( $n=5$ euploid mice and $n=4$ Ts65Dn mice) received a single subcutaneous injection $(150 \mu \mathrm{g} / \mathrm{g}$ body weight) of BrdU (5-bromo-2-deoxyuridine, Sigma), a marker of proliferating cells and their progeny ${ }^{21}$ in $0.9 \%$ $\mathrm{NaCl}$ solution. Animals were killed $2 \mathrm{~h}$ after the $\mathrm{BrdU}$ injection. The tissues of additional P2 animals ( $n=4$ euploid mice and $n=4$ Ts65Dn mice) were used for protein extraction and western blotting. For body weight evaluation, we used additional animals from our colony, aged from 2 up to 30 days. For each age group and genotype, body weight was measured in 20-30 animals. Each group had approximately the same composition of males and females. We additionally evaluated the weight of the heart and liver of P2 animals, to establish possible differences between euploid and trisomic mice and a correlation between organ and body weight. Such a correlation was not possible for the skin and small intestine, as the amount of sampled tissue inevitably varied in different animals.

\section{Histological Procedures}

Animals were anesthetized with ether, decapitated and the skin from the dorsum, heart, liver and small intestine were removed and fixed by immersion in Glyo-Fixx (Thermo Electron Corp., Waltham, MA, USA) for $48 \mathrm{~h}$. Samples were embedded in paraffin, cut with a microtome in $8-\mu \mathrm{m}$-thick sections that were attached to polylysine-coated slides. One out of two sections was mounted on a series of six slides so that each consecutive section of each slide was at a distance of twelve sections with respect to the preceding and following one. 


\section{BrdU immunohistochemistry}

Sections from the skin, heart, liver and small intestine of P2 animals and from the small intestine of P15 animals were processed for immunohistochemistry with a primary antibody anti-BrdU (1:100, Roche Applied Science, Mannheim, Germany). Detection was performed with a horseradish peroxidase-conjugated anti-mouse secondary antibody (1:200; Jackson Immunoresearch) and DAB kit (Vector Laboratories). Sections were counterstained with either the Nissl method or hematoxylin. Bright field images where taken with a Leitz Diaplan microscope equipped with a motorized stage and a Coolsnap-Pro digital camera (Media Cybernetics, Silver Spring, MD, USA).

\section{Cleaved caspase-3 immunohistochemistry}

Sections from the skin, heart, liver and small intestine of P2 animals and from the small intestine of P15 animals were processed for immunohistochemistry with a primary antibody anti-cleaved caspase-3 (1:200, Cell Signaling Technology, Danvers, MA, USA). Detection was performed with an anti-rabbit IgG FITC conjugated antibody (1:100, Sigma) and Hoechst counterstaining. Fluorescent images of the sections were taken with an Eclipse TE 2000-S microscope (Nikon, Tokyo, Japan) equipped with an AxioCam MRm (Zeiss, Oberkochen, Germany) digital camera.

\section{Ptch1 immunohistochemistry}

Sections from the small intestine of $\mathrm{P} 2$ and P15 mice were processed for Ptch1 immunohistochemistry with a primary antibody anti-patched (1:50, Abcam). Detection was performed with an anti-rabbit IgG CY3-conjugated antibody (1:200, Jackson Immunoresearch Laboratories) and Hoechst counterstaining. Fluorescent images of the sections were taken with an Eclipse TE 2000-S microscope (Nikon) equipped with an AxioCam MRm (Zeiss) digital camera.

\section{Measurements Cell number}

Acquired images of sections immunostained for BrdU and cleaved caspase-3 were analyzed with the utilities of the software image Pro-Plus (Media Cybernetics). BrdU-positive cells were counted in 1 out of 12 sections. A total of 6-10 sections were analyzed in each structure. Series of snaps from each sampled section were randomly acquired at a final magnification of $\times 312$. BrdU + cells and cells that were not immunopositive for BrdU (BrdU- cells) were counted within manually traced areas $\left(1400-1500 \mu \mathrm{m}^{2}\right.$ for the stratum germinativum and dermis of the skin; $700-800 \mu \mathrm{m}^{2}$ for the hair follicle; $45000-50000 \mu \mathrm{m}^{2}$ for the liver and heart; 5000 $5500 \mu \mathrm{m}^{2}$ for the intestinal cryptae; $1400-1500 \mu \mathrm{m}^{2}$ for the intestinal villi and muscularis externa). The number of $\mathrm{BrdU}+$ cells was expressed as the ratio over total cell number (sum of BrdU + and BrdU - cells) in the sampled area (labeling index (LI)). Total cell density was also evaluated and expressed as total number of cells $/ \mathrm{mm}^{2}$. Cleaved caspase-3positive cells were counted in 1 out of 12 sections. A total of four sections were analyzed in each structure. Series of snaps from each sampled region were randomly acquired at a final magnification of $\times 200$. Cleaved caspase-3-positive cells were counted within manually traced areas with the same size as those used for evaluation of BrdU + cells. All Hoechststained nuclei were also counted to evaluate total number of cells in the sampled area. Number of cleaved-caspase-3positive cells was expressed as the ratio over total cell number in the sampled area (LI).

\section{Ptch1 expression}

To assess differences in Ptch1 expression, sections from the small intestine immunostained for Ptch1 were analyzed with the utilities of the NIS-Elements AR software (Nikon). The mean intensity of Ptch1 signal was measured in the cryptal region of the intestine. Data were normalized to the signal to noise ratio of immunofluorescence as previously described. ${ }^{13}$

\section{Quantitative Real-Time PCR and Standard Reverse Transcription-PCR}

Total RNA was isolated from tissues with TriReagent (Sigma) according to the manufacturer's instructions. cDNA synthesis was achieved with $5.0 \mu \mathrm{g}$ of total RNA using M-MLV Reverse Transcriptase (Promega) and oligo(dT)16 primers according to the manufacturer's instructions. We used the primers that gave an efficiency which was close to $100 \% .{ }^{13}$ Real-time PCR was performed using a GoTaq qPCR Master Mix kit (Promega) according to the manufacturer's instructions in an iQ5 real-time PCR detection system (Bio-Rad).

\section{Western Blotting}

Total proteins from the skin, liver and intestine of P2 mice were obtained as previously described ${ }^{13}$ and protein concentration was estimated by the Lowry's method. Proteins $(100 \mu \mathrm{g})$ were subjected to electrophoresis on a 4-20\% Mini-PROTEAN TGX Precast Gel (Bio-Rad) and transferred to a Hybond ECL nitrocellulose membrane (Amersham Life Science). The following primary antibodies were used: anti-patched (1:50, Abcam) and anti-GAPDH (1:5000, Sigma) antibodies. Densitometric analysis of digitized images was performed with Scion Image software (Scion Corporation, Frederick, MD, USA) and intensity for each band was normalized to the intensity of the corresponding GAPDH band.

\section{Statistical Analysis}

Results are presented as the mean \pm standard error of the mean. Statistical testing was performed with the two-tailed Student's $t$-test. A probability level of $P<0.05$ was considered to be statistically significant. 


\section{RESULTS}

\section{Body and Organ Weight of Neonate and Juvenile Ts65Dn and Euploid Mice}

We evaluated the body weight of a large group of animals of our colony starting from the age of 2 days (P2) up to P30. The body weight of both Ts65Dn and euploid mice increased steadily and almost linearly during the first 2 weeks after birth (Figure 1). By P15, the body weight was approximately three times larger than on P2. The increase in body weight persisted in the following 2 weeks, so that by P30 the body weight was approximately twice as large as on P15. A comparison of Ts65Dn and euploid mice showed that on P2, Ts65Dn mice had a smaller body weight than the euploid counterparts (Figure 1). A comparison of the body weight before weaning, which in mice takes place approximately on P20, and after weaning (on P30) showed that at all examined ages, Ts65Dn mice had a smaller body weight than the euploid counterparts. The difference ranged between -10 and $-20 \%$.

Evaluation of the weight of the heart and liver at P2 showed that in Ts65Dn mice both organs had a reduced weight in comparison with euploid mice. The heart weight was $0.015 \pm 0.001 \mathrm{~g}$ in euploid mice, and $0.011 \pm 0.001 \mathrm{~g}$ in trisomic mice $(-27 \% ; P<0.011$, two-tailed $t$-test $)$. The liver weight was $0.107 \pm 0.018 \mathrm{~g}$ in euploid mice, and $0.059 \pm 0.001 \mathrm{~g}$ in trisomic mice $(-45 \%$; $P<0.015$, twotailed $t$-test). Evaluation of the ratio between the weight of each organ and total body weight showed no differences between euploid and trisomic mice, suggesting that the reduction in the weight of the heart and liver was proportional to that of total body weight.

\section{Cell Proliferation in the Skin of Ts65Dn and Euploid Mice at P2}

At P2, the skin from the back of both euploid and Ts65Dn mice showed the pattern present in adult mice. That is, the structure consisted of an epidermis, formed by a stratum corneum, stratum spinosum and stratum germinativum, and a dermis, formed by loosely arranged cells (Figures $2 \mathrm{a}$ and $\mathrm{b}$ ). The stratum germinativum consisted of a row of orderly organized cells. Though at this age, the skin of mice is almost glabrous, within the dermis numerous hair follicles were recognizable (Figures $2 \mathrm{a}$ and $\mathrm{b}$ : white arrow).

Numerous BrdU + cells were found in the skin of P2 animals. Most of these cells were located in the stratum germinativum and hair follicles, though scattered $\mathrm{BrdU}+$ cells were also present in the dermis (Figures 2a-d). In euploid mice, the number of BrdU + cells out of the total cell number (LI) was approximately 0.22 in the stratum germinativum (Figure 2e), 0.60 in the hair follicles (Figure 2g) and 0.06 in the dermis (data not shown). A comparison of skin sections from Ts65Dn and euploid animals showed patent differences in the number of BrdU+ cells, with Ts65Dn mice exhibiting fewer BrdU + cells than euploid mice in the stratum germinativum (Figures $2 \mathrm{a}$ and $\mathrm{b}$ ) and hair follicles (Figures $2 \mathrm{c}$ and $\mathrm{d}$ ). Evaluation of the LI

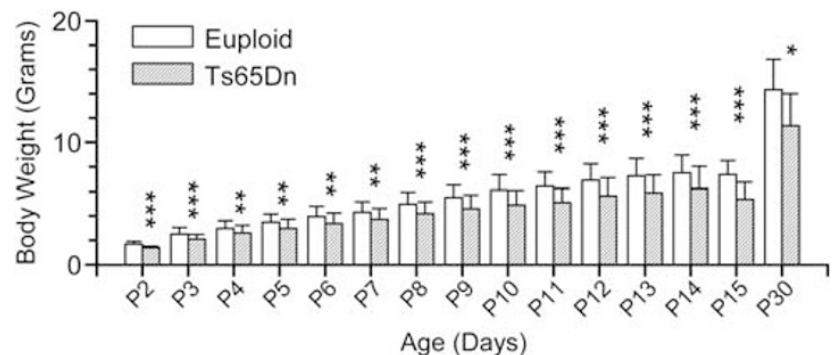

Figure 1 Body weight of euploid and Ts65Dn mice. The graph shows the body weight at the indicated ages from postnatal day 2 (P2) up to 1 month of age (P30). For each age group, data refer to 20-30 animals of each genotype. Bars are the mean \pm s.d. ${ }^{*} P<0.05 ;{ }^{*} P<0.01 ;{ }^{*}{ }^{*} P<0.001$ (two-tailed Student's $t$-test).

showed that Ts65Dn mice had a notably smaller LI than euploid mice both in the stratum germinativum (Figure 2e) and hair follicles (Figure $2 \mathrm{~g}$ ). Evaluation of the LI in the dermis showed that Ts65Dn mice also had a reduced LI $(\mathrm{LI}=0.03)$ compared with euploid mice in this layer, although the difference was only marginally significant $(P=0.054$; two-tailed $t$ test; data not shown). Evaluation of total cell density (number of BrdU + plus BrdU - cells per unit area) showed no difference between Ts65Dn and euploid mice in the stratum germinativum (Figure 2f), hair follicles (Figure 2h) and dermis (data not shown).

\section{Cell Proliferation in the Heart of Ts65Dn and Euploid Mice at P2}

$\mathrm{BrdU}+$ cells were present in all regions of the heart of P2 animals. We initially evaluated the LI of BrdU + cells, separately, in the left and right heart walls and in the septum. As there were no differences in the LI of all examined regions, data were pooled together. In euploid mice, the overall LI had a value of 0.23 (Figure 3c). A comparison of heart sections from Ts65Dn and euploid animals showed patent differences in the number of BrdU + cells, with Ts65Dn mice exhibiting fewer BrdU + cells than euploid mice (Figures $3 \mathrm{a}$ and $\mathrm{b}$ ). Evaluation of the LI showed that Ts65Dn mice had a smaller LI than euploid mice $(-20 \%)$ (Figure 3c). Evaluation of total cell density showed no difference between Ts65Dn and euploid mice (Figure 3d).

\section{Cell Proliferation in the Liver of Ts65Dn and Euploid Mice at P2}

In mice aged 2 days, among the four lobi forming the liver, the median and left lobi were the most prominent. Thus, in the current study, samples from these lobi were utilized. In the liver of P2 mice, there were numerous BrdU + cells. In euploid mice, the LI was approximately 0.28 (Figure 4c). A comparison of liver sections from P2 animals showed patent differences in the number of $\mathrm{BrdU}+$ cells, with Ts65Dn mice exhibiting fewer BrdU + cells than euploid mice (Figures $4 \mathrm{a}$ and $\mathrm{b}$ ). Evaluation of the LI showed that Ts65Dn mice had a notably smaller LI than euploid mice 


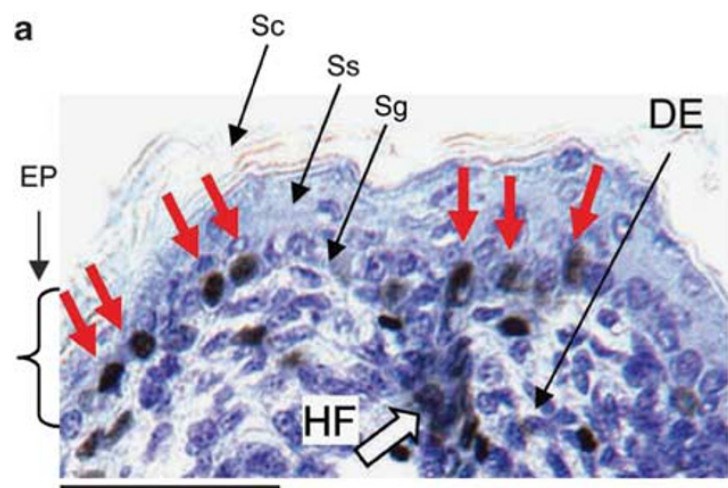

Euploid

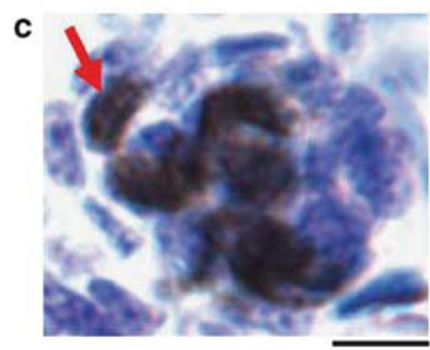

Euploid
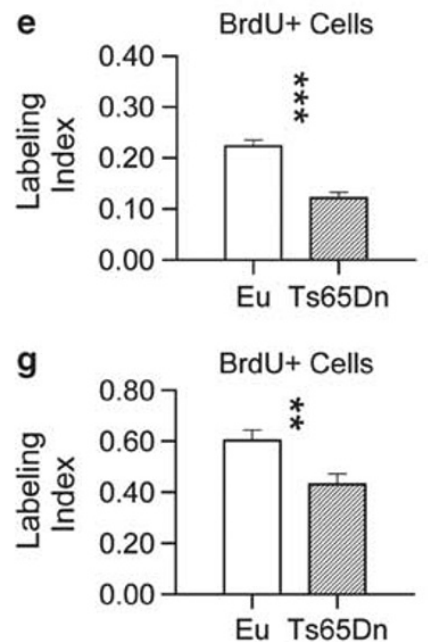

b

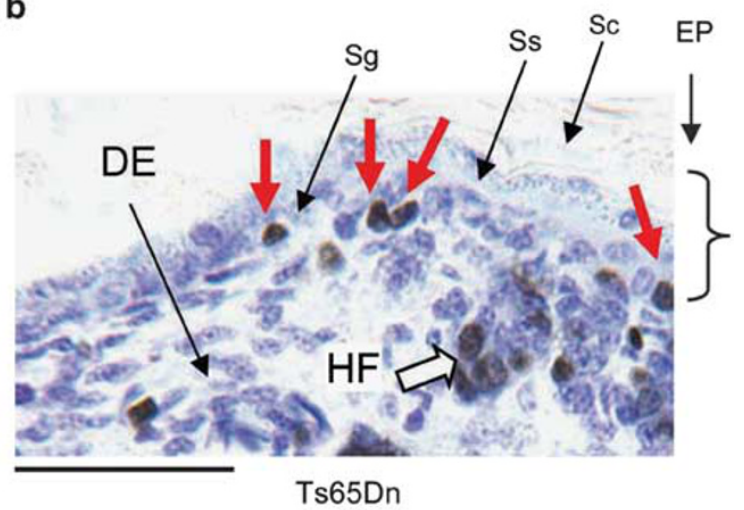

d

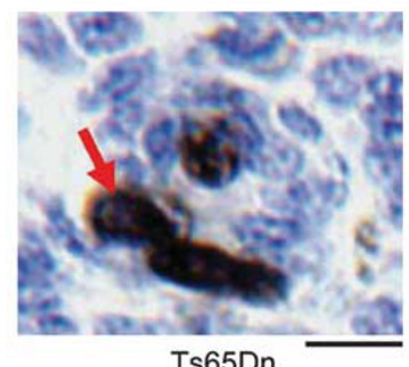

f

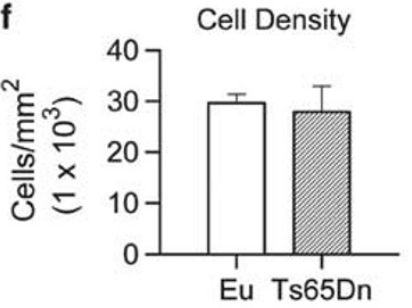

h

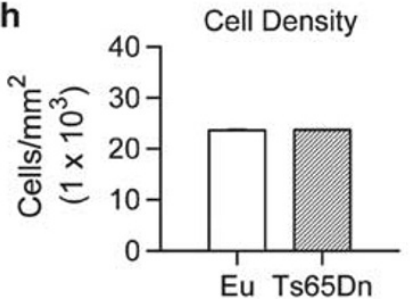

Figure 2 Cell proliferation in the skin of P2 mice. (a-d) Examples of sections immunostained for BrdU (5-bromo-2-deoxyuridine) and counterstained with the Nissl method from the skin of an euploid $(\mathbf{a}, \mathbf{c})$ and a Ts65Dn (b, d) mouse. Images in $\mathbf{c}$ and $\mathbf{d}$ are examples of hair follicles seen at higher

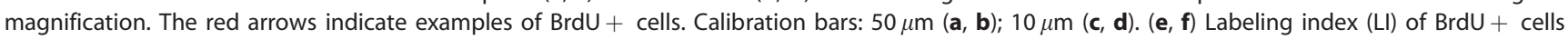
(e) and cell density (f) in the stratum germinativum. (g, h) LI of BrdU + cells ( $\mathbf{g})$ and cell density (h) in the hair follicles of P2 euploid and Ts65Dn mice. Bars are the mean \pm s.d. ${ }^{* *} P<0.01$; ${ }^{* *} P<0.001$ (two-tailed Student's t-test). DE, dermis; EP, epidermis; HF, hair follicle; Sc, stratum corneum; Sg Stratum germinativum; Ss, stratum spinosum.

( $-53 \%$; Figure 4c). Evaluation of total cell density showed that Ts65Dn mice had a smaller cell density $(-12 \%)$ than euploid mice (Figure 4d).

\section{Cell Proliferation in the Intestine of Ts65Dn and Euploid Mice at P2}

Numerous BrdU + cells were present in the cryptal region (see the region bordered by dashed lines in Figure $5 \mathrm{a}$ ) and in the villi (Figure 5a). Scattered $\mathrm{BrdU}+$ cells were present underneath the cryptal region, within the muscularis externa.

In euploid mice, the LI was approximately 0.35 in the cryptal region and 0.08 in the villi (Figures $5 \mathrm{c}$ and e). A comparison of sections from the intestine of euploid and Ts65Dn mice clearly showed that the latter had fewer BrdU + cells in all layers (Figures $5 \mathrm{a}$ and $\mathrm{b}$ ). This was particularly evident in the cryptal region, which is rich in numerous proliferating cells. Evaluation of the LI showed that Ts65Dn 


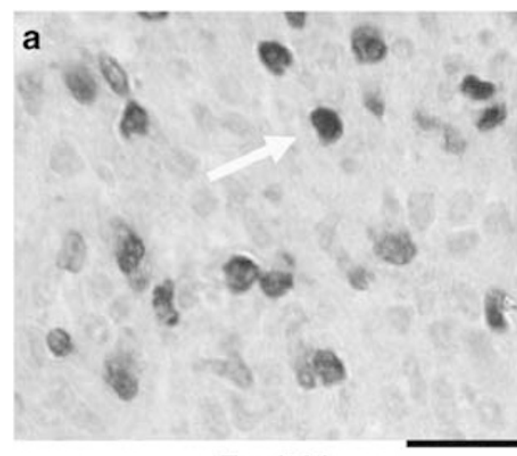

Euploid

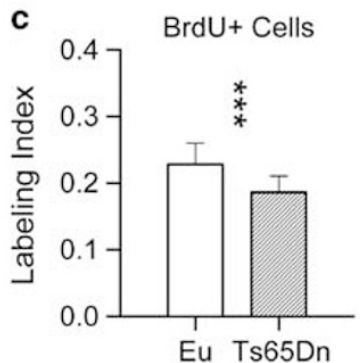

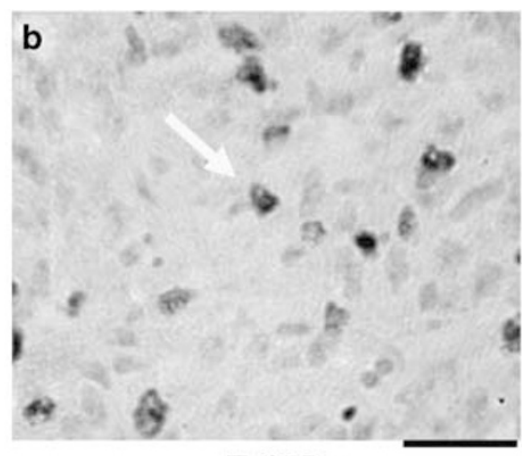

Ts65Dn

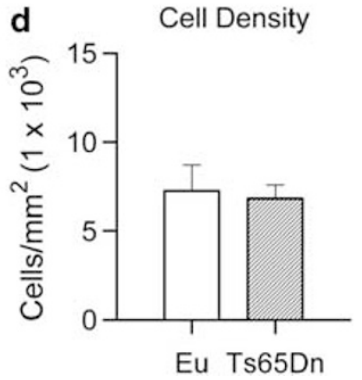

Figure 3 Cell proliferation in the heart of P2 mice. (a, b) Examples of sections immunostained for BrdU (5-bromo-2-deoxyuridine) and counterstained with hematoxylin from the ventricular wall of an euploid (a) and a Ts65Dn (b) mouse. The white arrows indicate examples of BrdU + cells. Calibration bars: $25 \mu \mathrm{m}$. (c, d) Labeling index (LI) of BrdU + cells (c) and cell density (d) in the heart. Bars are the mean \pm s.d. ${ }^{* * *} P<0.001$ (two-tailed Student's $t$-test).
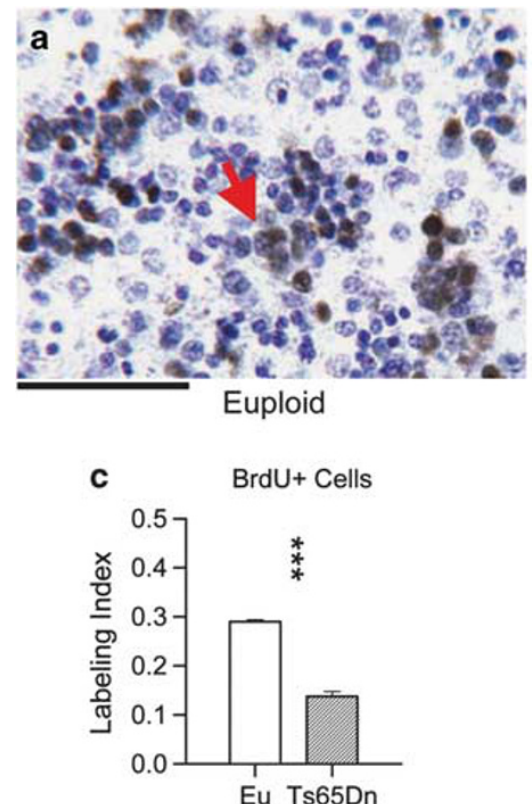
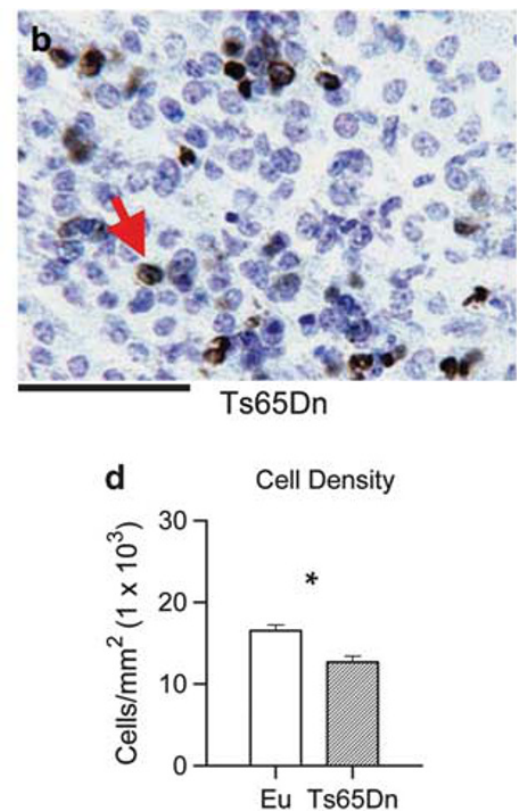

Figure 4 Cell proliferation in the liver of P2 mice. (a, b) Examples of sections immunostained for BrdU (5-bromo-2-deoxyuridine) and counterstained with the Nissl method from the liver of an euploid (a) and a Ts65Dn (b) mouse. The red arrows indicate examples of BrdU + cells. Calibration bars: $50 \mu \mathrm{m}$. (c, d) Labeling index (LI) of BrdU + cells (c) and cell density (d) in the liver. Bars are the mean \pm s.d. ${ }^{*} P<0.05 ;{ }^{* * *} P<0.001$ (two-tailed Student's $t$-test).

mice had a smaller LI than euploid mice both in the cryptal region $(-28 \%)$ (Figure $5 \mathrm{c})$ and the villi $(-44 \%$; Figure 5e). Evaluation of the LI in the muscularis externa showed that the LI was also smaller $(-40 \%)$ in Ts65Dn compared with euploid mice in this layer (data not shown). Evaluation of total cell density showed that, although no differences were present between Ts65Dn and euploid mice in the cryptal region (Figure 5d), Ts65Dn mice had a reduced 

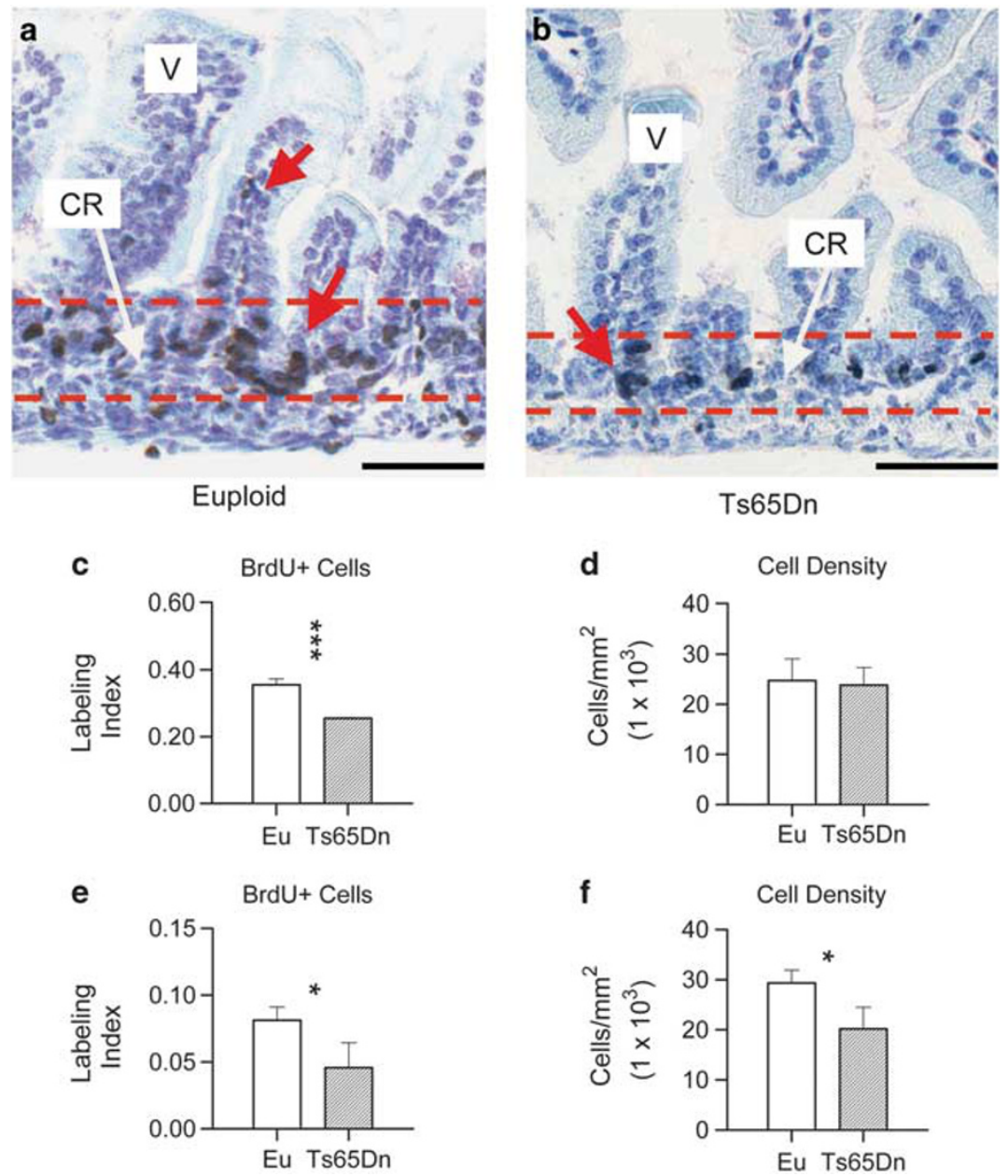

Figure 5 Cell proliferation in the intestine of P2 mice. (a, b) Examples of sections immunostained for BrdU (5-bromo-2-deoxyuridine) and counterstained with the Nissl method from the intestine of an euploid (a) and a Ts65Dn (b) mouse. The red arrows indicate examples of BrdU + cells. Calibration bars: $50 \mu \mathrm{m}$. (c-f) Labeling index (LI) of BrdU + cells in the cryptal region (c) and in the villi (e), and cell density in the cryptal region (d) and villi (f) of P2 euploid and Ts65Dn mice. Bars are the mean \pm s.d. ${ }^{*} P<0.05 ;{ }^{* * *} P<0.001$ (two-tailed Student's $t$-test). CR, cryptal region; $\mathrm{V}$, villus.

cell density $(-31 \%)$ in the villi compared with euploid mice (Figure 5f).

\section{Cell Proliferation in the Intestine of Ts65Dn and Euploid Mice at P15}

To establish whether the proliferation defect observed at P2 was retained with age, we examined cell proliferation in the intestine, as this organ exhibits a continuous renewal throughout life. In the intestine of P15 mice, we found numerous BrdU + cells. These cells were mainly located in the cryptal region, but scattered cells were also present in the villi (Figures $6 \mathrm{a}$ and $\mathrm{b}$ ). In euploid mice, the LI was approximately 0.30 in the cryptal regions and 0.10 in the villi.

Qualitative observation of Figures $6 a$ and b clearly shows that Ts65Dn mice also had fewer BrdU + cells than euploid mice at this age. Quantification of the number of BrdU+ cells out of the total cell number showed that Ts65Dn mice had fewer proliferating cells both in the cryptal region $(-36 \%$; Figure $6 c)$ and the villi $(-26 \%$; Figure 6e), though in the villi this difference was not statistically significant. Evaluation of total cell density showed no differences between Ts65Dn and euploid mice both in the cryptal region (Figure 6d) and the villi (Figure 6f).

\section{Apoptotic Cell Death in Peripheral Tissues of Ts65Dn and Euploid Mice}

Apoptotic cell death is a physiological phenomenon that accompanies cell proliferation. Programmed cell death eliminates the surplus of newborn cells, as well as postmitotic cells, thereby regulating the final number of cells in a given tissue. To establish whether there was an imbalance in programmed cell death in the tissues of trisomic mice, we used immunohistochemistry for cleaved caspase-3, a marker of apoptotic cells. The number of apoptotic cells in different tissues was normalized by expressing it as the ratio of apoptotic cells in a given area out of the total number of cells in the same area (LI of apoptotic cells). 

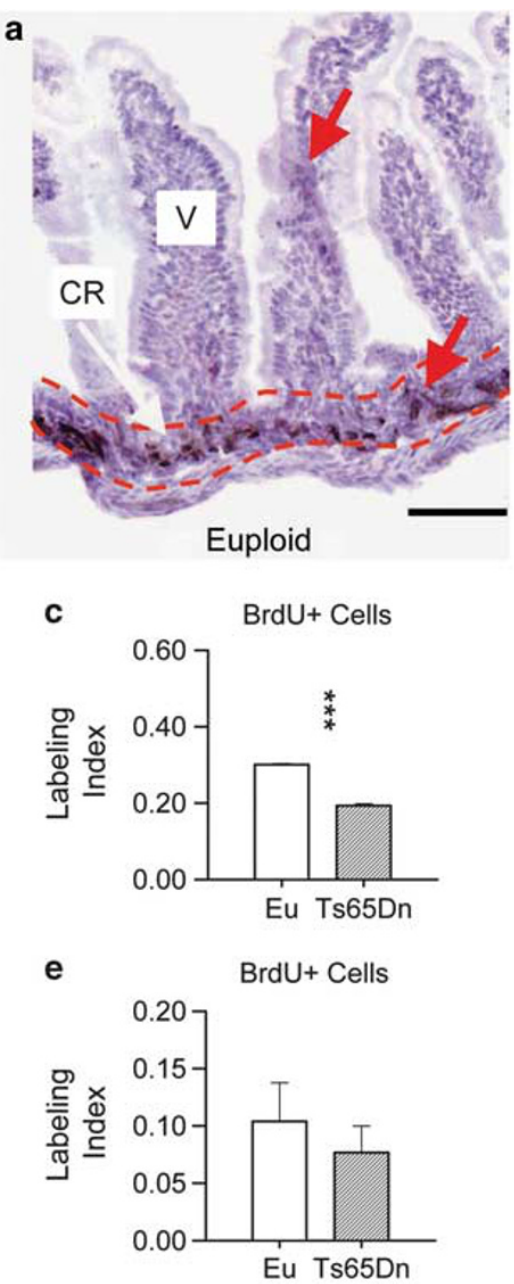
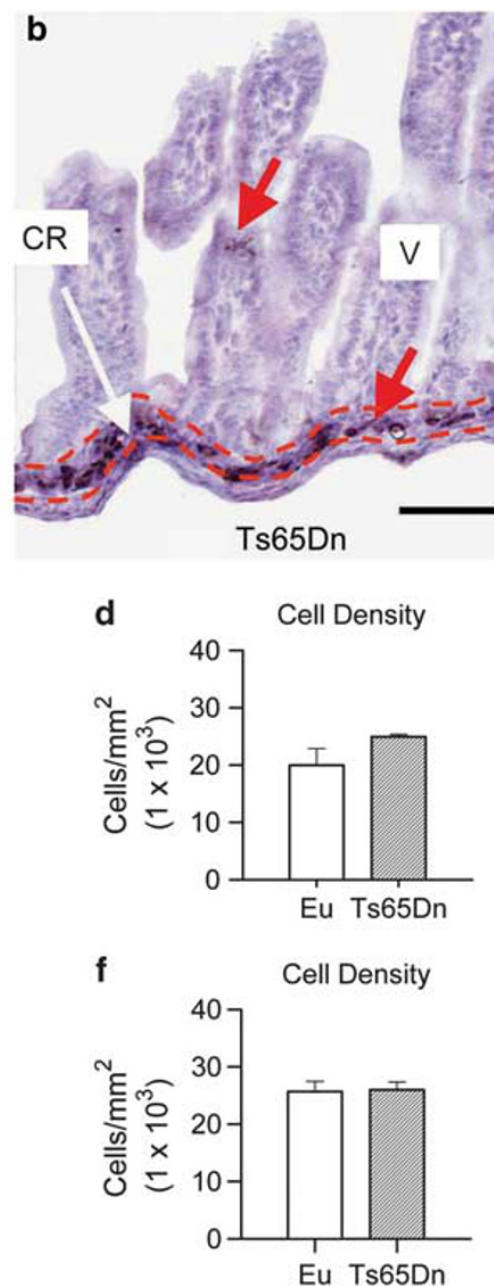

Figure 6 Cell proliferation in the intestine of P15 mice. (a, b) Examples of sections immunostained for BrdU (5-bromo-2-deoxyuridine) and counterstained with the Nissl method from the intestine of an euploid (a) and a Ts65Dn (b) mouse. The red arrows indicate examples of BrdU + cells. Calibration bars: $50 \mu \mathrm{m}$. (c-f) Labeling index (LI) of BrdU + cells in the cryptal region (c) and in the villi (e), and cell density in the cryptal region (d) and villi (f) of P2 euploid and Ts65Dn mice. Bars are the mean \pm s.d. ${ }^{* *} P<0.001$ (two-tailed Student's $t$-test). CR, cryptal region; V, villus.

In all examined tissues of $\mathrm{P} 2$ euploid mice, we found that the LI of apoptotic cells was extremely low, with a magnitude of about 0.01 in the skin (Figure 7a) and heart (Figure 7b), and even lower in the liver (Figure 7c) and intestine (Figures $7 \mathrm{~d}$ and e). This means that 1 or less than 1 out of 100 cells was dying due to the process of apoptosis. A comparison of the number of apoptotic cells in Ts65Dn and euploid mice showed no difference between groups in any of the examined tissues (Figure 7), indicating that the reduced number of $\mathrm{BrdU}+$ cells seen in the various tissues of Ts65Dn mice was not attributable to an increase in cell death. Similarly to P2 mice, P15 mice showed no differences in apoptotic cell death in the intestine (data not shown).

Increased Expression of Ptch1 and Impaired Shh Signaling in Peripheral Tissues of Trisomic Mice

As we previously found that neural precursor cells from the SVZ of Ts65Dn mice exhibit deregulation of the Shh pathway due to over expression of its receptor Ptch $1,{ }^{13}$ we evaluated the expression of Ptch1 in the peripheral tissues of Ts65Dn mice. Quantification of Ptch1 protein levels by western blotting in P2 animals showed that Ptch1 was over expressed in the skin, liver and intestine (Figure 8a) of Ts65Dn compared with euploid mice.

We performed a gene expression study, by quantitative reverse transcriptase PCR (RT-qPCR), to establish whether genes known to be involved in the Shh pathway exhibited an altered expression in trisomic tissues. We found that the Gli family members Gli1 (Figure 8b) and Gli2 (data not shown), which are transcription factors functioning as Shh effectors, showed a significant downregulation in all examined trisomic tissues. Looking at $\mathrm{MycN}$ (a Gli target gene) expression, we found that it was downregulated in trisomic tissues (Figure 8b). Additionally, the expression of FoxM1, an indirect Gli target that promotes cell cycle progression at the $\mathrm{G}_{2} / \mathrm{M}$-phase transition, was also downregulated (Figure $8 \mathrm{~b}$ ). 


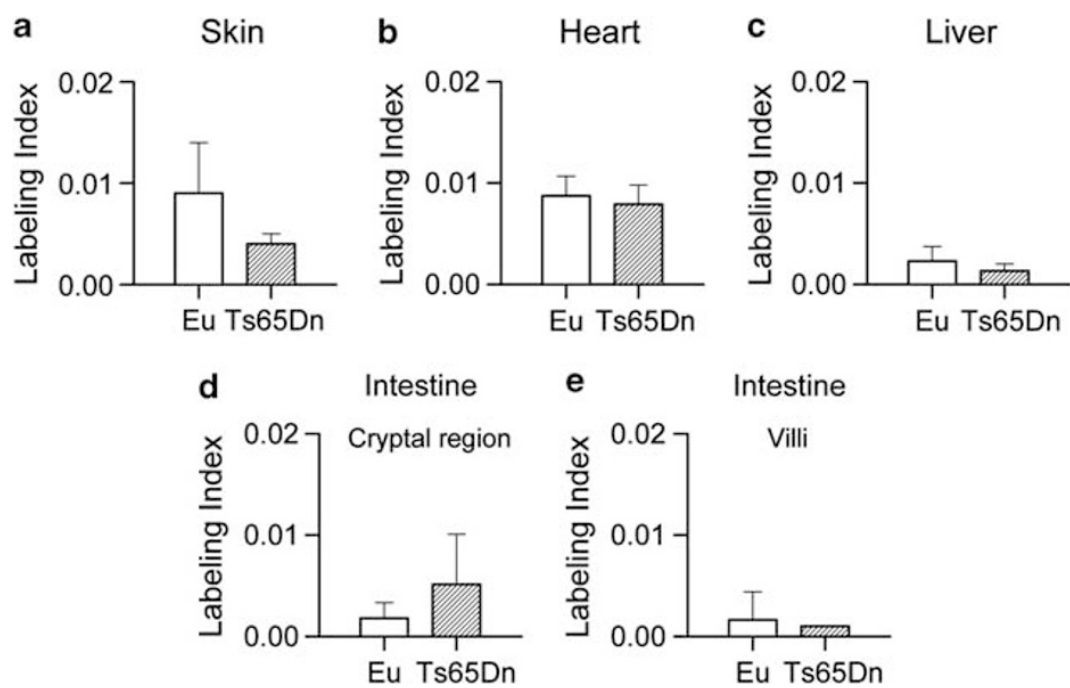

Figure 7 Apoptotic cell death in the peripheral tissues of P2 mice. Labeling index of apoptotic cells, evaluated with cleaved-caspase 3 immunohistochemistry in the skin (a), heart (b), liver (c) and intestine (d). Bars are the mean \pm s.d. No differences in apoptotic cell death were found in the examined tissues.

These observations clearly indicate derangement of the Shh pathway in tissues from Ts65Dn mice.

We quantified Ptch1 expression in the cryptal region of the intestine, a region which is particularly rich in proliferating precursors in P2 and P15 animals, to establish whether Ptch1 over expression was retained with age. A comparison of P2 and P15 euploid and Ts65Dn mice showed that the latter had a larger expression of Ptch1 than their euploid counterparts at both examined ages (Figures 9e and f), indicating that this defect is retained with age.

\section{DISCUSSION}

\section{Body Growth Impairment in Trisomic Mice}

In mammals, the rate of somatic growth is rapid in early postnatal life but then slows with age, approaching zero as the animal approaches adult body size. Growth deceleration is mainly caused by a decrease in the rate of cell proliferation. ${ }^{22}$ In euploid mice, we found a fast body weight increase from P2 to P15. The weight gain persisted up to P30 (the oldest age examined here), though in a less steep manner. No gross developmental delay appears to be present during gestation in Ts65Dn compared with euploid mice. ${ }^{6,23}$ However, in the period P2-P15 and at P30, we found that, in agreement with previous evidence, ${ }^{23}$ Ts65Dn mice had a smaller body weight than their euploid counterparts. These data indicate that in Ts65Dn mice growth impairment, which is apparent shortly after birth, is retained in adulthood. Ts65Dn mice exhibited notable proliferation impairment in various peripheral tissues at $\mathrm{P} 2$, a time of intense cell proliferation. This general decrease in proliferation suggests that the small body mass of trisomic mice is due to a reduced production of the cells that form the peripheral organs. In agreement with this idea, we found that the heart and liver of trisomic mice had a reduced weight in comparison with euploid mice. Reduced growth rate, short stature and brachycephaly are typical features of individuals with DS. ${ }^{9,10}$ Based on current findings in trisomic mice, these phenotypic features are likely to be underpinned by a generalized proliferation defect.

\section{Prominent Proliferation in Peripheral Tissues of Neonate and Juvenile Mice}

Skin proliferation is very prominent during the period of body growth, with continued proliferation in adulthood because of the rapid turnover of differentiated cells. ${ }^{24}$ In the mouse, cardiomyocyte reduplication largely takes place before birth and continues up to the first 2-3 postnatal days. In the following days, cell division ceases and DNA synthesis contributes to cardiomyocyte binucleation. ${ }^{25}$ Similarly to the heart, the liver largely develops before birth and proliferation of haepatoblasts rapidly decreases in the early postnatal days. ${ }^{26}$ Morphogenesis of the intestine in mice begins in the embryonic period and continues in the early postnatal period. ${ }^{27,28}$ Cell proliferation, however, continues throughout life, as the mucosa needs a continuous renewal due to the mechanical stress exerted by the intestinal contents.

We found numerous BrdU + cells in the skin, heart, liver and intestine of P2 mice. Evaluation of the LI in euploid mice gave values of 0.22 in the stratum germinativum of the skin, 0.60 in the hair follicles, 0.23 in the heart, 0.28 in the liver and 0.35 in the cryptal region of the intestine. These numbers indicate that the cells that had incorporated BrdU represented $22-60 \%$ of the total cell number. Cells in mouse tissues have a cell cycle of 12-24 h. ${ }^{14,29-32}$ Considering that BrdU labels cells in the S-phase of the cell cycle, the cells found $2 \mathrm{~h}$ after a single BrdU injection obviously do not reflect the whole cohort of cycling cells. 
a

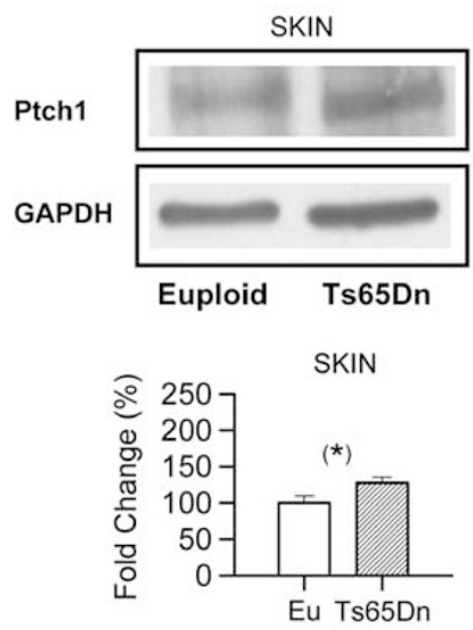

b
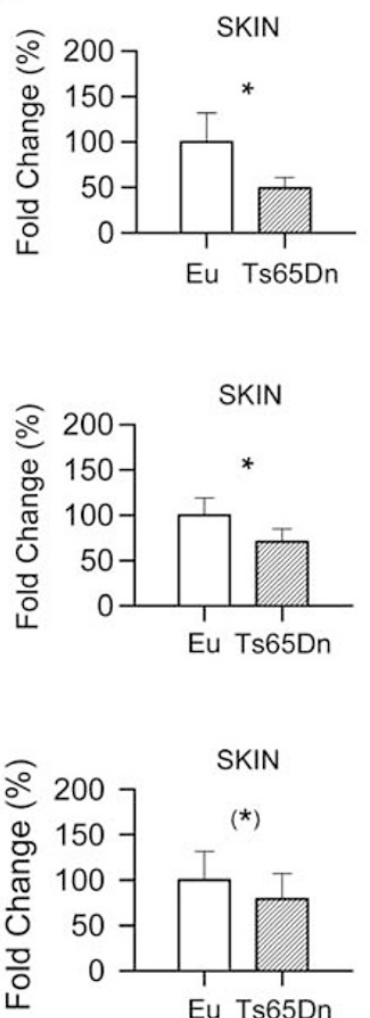

Ptch1

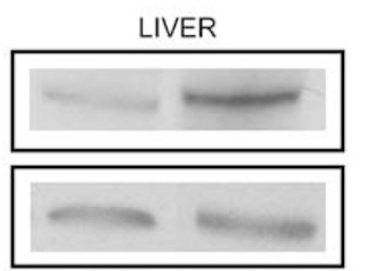

Euploid Ts65Dn

LIVER

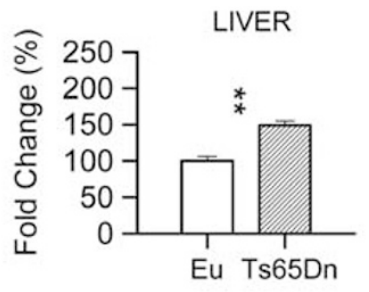

Gli1

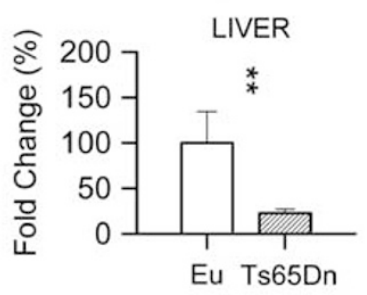

$\mathrm{MycN}$
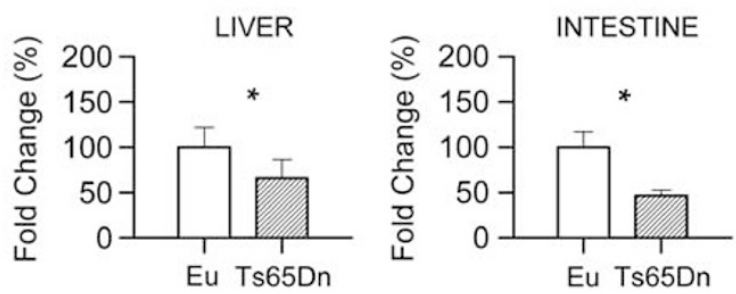

FoxM1

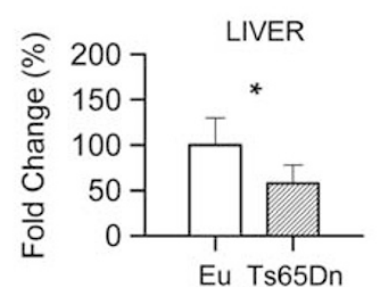

INTESTINE

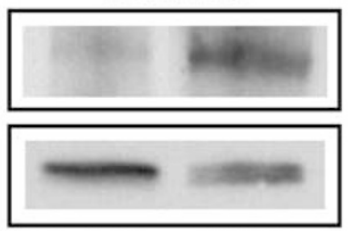

Euploid Ts65Dn

INTESTINE
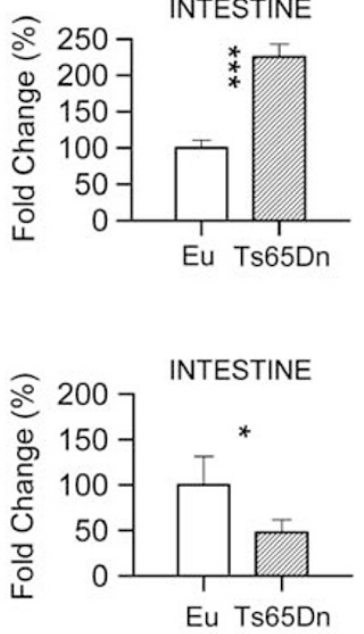

Eu Ts65Dn

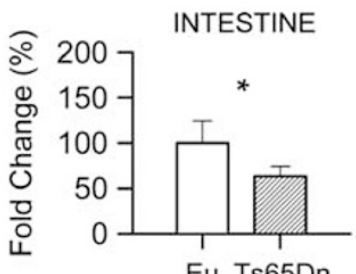

Figure 8 Expression of patched1 (Ptch1) and downstream elements of the sonic hedgehog (Shh) pathway in peripheral tissues of P2 mice. (a) Quantification by western blot analysis of Ptch1 protein levels in the skin, liver and intestine of euploid and Ts65Dn mice. (b) Quantification by RT-qPCR of Gli1, MycN and FoxM1 expression in the skin, liver and intestine of euploid and Ts65Dn mice. Values in Ts65Dn mice are expressed as fold difference in comparison with euploid mice. Bars are the mean \pm s.d. $\left({ }^{*}\right) P<0.06 ;{ }^{*} P<0.05 ;{ }^{*} P<0.01 ;{ }^{* * *} P<0.001$ (two-tailed Student's $t$-test).

This implies that the growth fraction, ie, the total number of actively dividing cells, in the analyzed tissues of P2 animals is larger than $20-60 \%$. This is not surprising, considering the immaturity of mice at birth and the fact that tissue formation largely continues in the first postnatal period.

\section{Severe Proliferation Impairment in Peripheral Tissues of Neonate and Juvenile Ts65Dn Mice}

In the skin of $\mathrm{P} 2$ trisomic mice, we found a reduced number of BrdU + cells in the stratum germinativum $(-46 \%)$, hair follicle $(-29 \%)$ and dermis $(-44 \%)$, in comparison with euploid mice, indicating proliferation impairment in all skin 

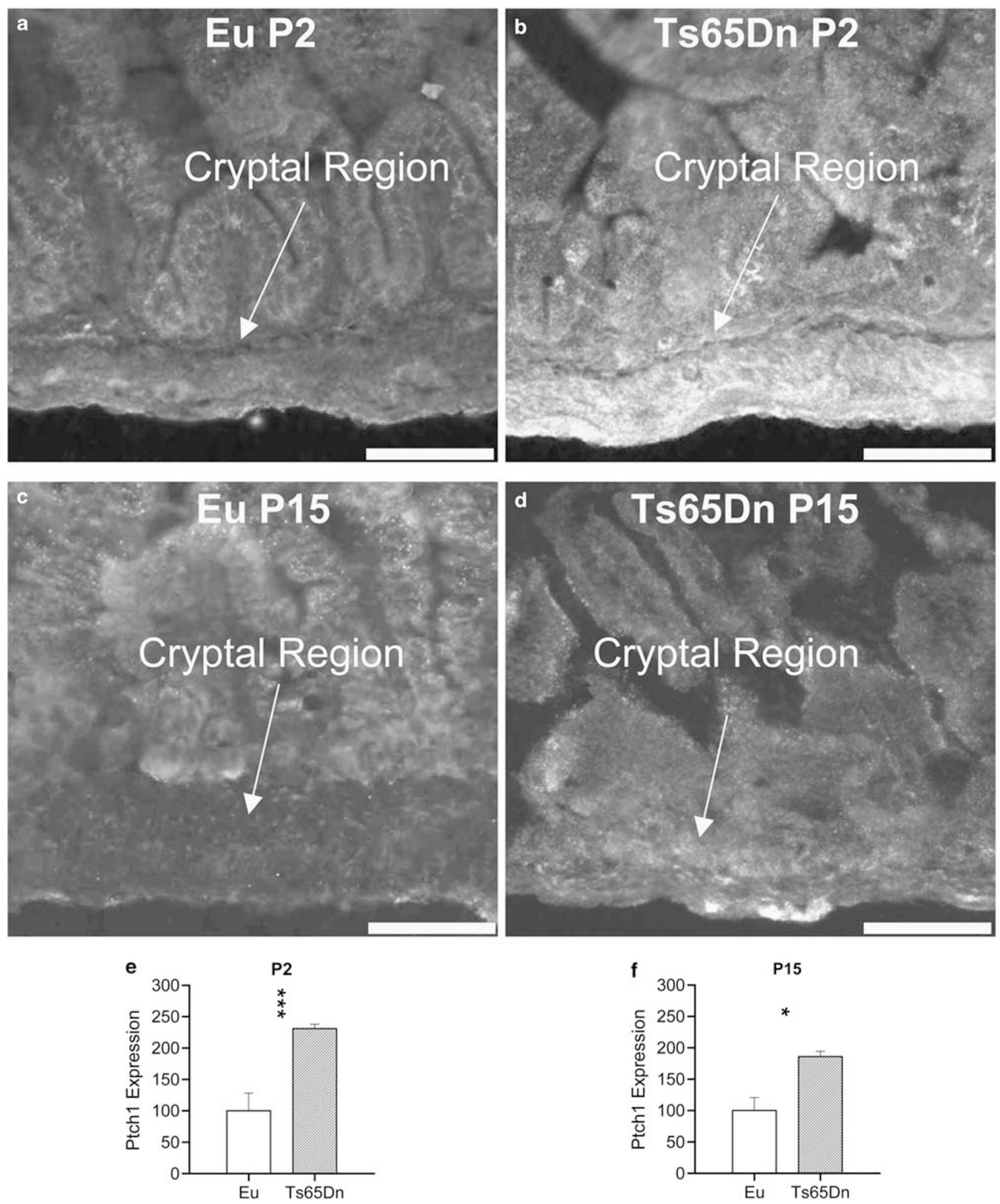

Figure 9 Patched1 (Ptch1) expression in the intestine of P2 and P15 mice. (a-d) Examples of sections immunostained for Ptch1 from the intestine of a P2 euploid (a), a P2 Ts65Dn (b), a P15 euploid (c) and a P15 Ts65Dn (d) mouse. Calibration bars: $50 \mu \mathrm{m}$. (e, f) Quantification of Ptch1 immunoreactivity in the cryptal region of the intestine of P2 (e) and P15 (f) mice. At each age, values in Ts65Dn mice expressed as multiple of the euploid counterparts. Bars are the mean \pm s.d. ${ }^{*} P<0.05 ;{ }^{* * *} P<0.001$ (two-tailed Student's $t$-test). 
germinative niches. There are no investigations on skin defects in Ts65Dn mice. However, subjects with DS exhibit various dermatological problems that include hyperkeratosis, xerosis, dermatitis and folliculitis. In addition, hair loss arises more frequently in individuals with DS., ${ }^{9,11}$ The reduced proliferation potency observed in the skin of Ts65Dn mice suggests that these defects may be underpinned by an abnormal formation of the different skin components.

In the heart of P2 Ts65Dn mice, there was a reduced number of BrdU + cells $(-20 \%)$ in comparison with euploid mice, indicating a reduced formation of cardiomyocytes. Ts65Dn mice show gross vascular abnormalities, interventricular septal defects and abnormal muscle composition in the cardiac valves. ${ }^{33}$ The reduced proliferation rate of cardiomyocites in trisomic mice may be one of the determinants of their cardiac morphological defects. Translation of these data to humans suggests that congenital heart defects in children with DS may be underpinned by proliferation defects during heart formation.

In the liver of Ts65Dn mice, we found notable proliferation impairment $(-53 \%)$ and a reduced cell density, indicating severe developmental defects of this organ. DS is not usually thought of in association with significant infantile liver disease. However, some reports indicate that children with DS may have severe liver disease at birth or within the first few weeks of life, ${ }^{34,35}$ and cirrhosis, granulomas and acidophilic bodies are twice as common among DS patients than control patients. ${ }^{36}$ The developmental impairment of the liver observed in trisomic mice may provide the morphofunctional substrate of liver pathology in children with DS.

In the intestine of P2 trisomic mice, there was a reduced number of BrdU + cells in the cryptal region, villi and the muscularis externa, indicating proliferation impairment in all intestinal germinative niches. The crypts at the base of the villi contain stem cells that continuously divide by mitosis, producing more stem cells and cells that migrate up the surface of the villus. These cells differentiate into columnar epithelial cells, which are responsible for digestion and absorption, and goblet cells, that secrete mucous. Precursor proliferation reduction in the cryptal region may lead to abnormal mucosa formation and, consequently, to secretion/ absorption problems. Proliferating cells in the muscularis externa might represent precursor cells of neurons of the myenteric plexus, as proliferation of neurons of the myenteric plexus still occurs in the postnatal period. ${ }^{37}$ The reduced proliferation rate of these cells in trisomic mice may lead to defects in intestinal motility. Common malformations in children with DS are those of the gastrointestinal tract, such as duodenal atresia, Hirschsprung's disease and tracheoesophageal fistula. ${ }^{10}$ Current evidence in a mouse model of DS suggests that the gastrointestinal defects in individuals with DS may be linked to proliferation impairment during the development of the intestine, and that the persistence of these defects may be due to poor intestinal repair at later life stages.

\section{Dysregulation of Ptch1 Expression may be a Common Mechanism that Underlies Proliferation Impairment in the Trisomic Condition}

Hedgehog signal activation is required for normal proliferation and differentiation in the intestine, ${ }^{38}$ liver $^{39}$ and heart. ${ }^{40}$ In the skin, the Shh pathway is crucial for the maintenance of the stem cell population, and for the regulation of hair follicle development. ${ }^{41,42}$

In the skin, liver and intestine of trisomic mice, we found over expression of Ptch1, suggesting that inhibition of the mitogenic Shh pathway may underlie proliferation impairment. Consistently with this hypothesis, we found a reduced expression of Gli1, Gli2, MycN and FoxM1, key genes involved in Shh signaling. The finding that $\mathrm{MycN}$ and FoxM1, two factors that enhance proliferation, were downregulated in trisomic tissues accounts for the reduced proliferation rate observed in these tissues and suggests that the defective proliferation of peripheral trisomic tissues is ascribable to cell cycle alterations.

Cerebellar granule cell precursors, ${ }^{5}$ precursors from the neural crest ${ }^{43}$ and from the SVZ ${ }^{13}$ of trisomic mice exhibit a significant deficit in the Shh-induced mitogenic response. We have previously shown that this defect is related to an increased expression of Ptch $1 .{ }^{13}$ Current evidence of an increased expression of Ptch1 in peripheral tissues of trisomic mice suggests that an abnormal response to Shh may be a common mechanism underlying the widespread proliferation impairment that characterizes the brain and peripheral tissues in the trisomic condition.

\section{Conclusions}

Our findings show that, in all examined tissues, Ts65Dn mice exhibited a notable reduction in proliferation rate, confirming our hypothesis that proliferation impairment may be a generalized feature of the trisomic condition. Embryonic stem (ES) cells are pluripotent cells derived from the inner cell mass of the blastocyst. ES cells give origin to multipotent stem cells of the three primary germ layers (ectoderm, endoderm and mesoderm). These multipotent stem cells give origin to stem cells of the different body tissues. We found that trisomic mice had reduced proliferation potency in the skin, which derives from the ectoderm, in the heart, which derives from the mesoderm, and in the liver and intestine, which derive from the endoderm, indicating that proliferation was impaired in tissues derived from all germ layers.

Given that individuals with DS share many genetic and phenotypic features with Ts65Dn mice, it is likely that they also share a similar generalized proliferation defect. DS is characterized by, in addition to mental retardation, a reduced growth and derangement of numerous body functions. Perturbation of this basic developmental process, cell proliferation, may be a critical determinant that contributes to the manifold aspects of this pathology. 


\section{ACKNOWLEDGEMENTS}

This work was supported by a grant from the 'Fondation Jerome Lejeune' to RB.

\section{DISCLOSURE/CONFLICT OF INTEREST}

The authors declare no conflict of interest.

1. Rachidi M, Lopes C. Mental retardation and associated neurological dysfunctions in Down syndrome: a consequence of dysregulation in critical chromosome 21 genes and associated molecular pathways. Eur J Paediatr Neurol 2008;12:168-182.

2. Haydar TF, Nowakowski RS, Yarowsky PJ, et al. Role of founder cell deficit and delayed neuronogenesis in microencephaly of the trisomy 16 mouse. J Neurosci 2000;20:4156-4164.

3. Lorenzi HA, Reeves RH. Hippocampal hypocellularity in the Ts65Dn mouse originates early in development. Brain Res 2006:1104:153-159.

4. Contestabile A, Fila T, Ceccarelli C, et al. Cell cycle alteration and decreased cell proliferation in the hippocampal dentate gyrus and in the neocortical germinal matrix of fetuses with Down syndrome and in Ts65Dn mice. Hippocampus 2007;17:665-678.

5. Roper RJ, Baxter LL, Saran NG, et al. Defective cerebellar response to mitogenic Hedgehog signaling in Down [corrected] syndrome mice. Proc Natl Acad Sci USA 2006;103:1452-1456.

6. Chakrabarti L, Galdzicki Z, Haydar TF. Defects in embryonic neurogenesis and initial synapse formation in the forebrain of the Ts65Dn mouse model of Down syndrome. J Neurosci 2007;27:11483-11495.

7. Guidi S, Bonasoni $P$, Ceccarelli $C$, et al. Neurogenesis impairment and increased cell death reduce total neuron number in the hippocampal region of fetuses with Down syndrome. Brain Pathol 2008;18:180-197.

8. Rachidi M, Lopes C. Mental retardation in Down syndrome: from gene dosage imbalance to molecular and cellular mechanisms. Neurosci Res 2007;59:349-369.

9. Roizen NJ, Patterson D. Down's syndrome. Lancet 2003;361: 1281-1289.

10. Noble J. Natural history of Down's syndrome: a brief review for those involved in antenatal screening. J Med Screen 1998;5:172-177.

11. Madan V, Williams J, Lear JT. Dermatological manifestations of Down's syndrome. Clin Exp Dermatol 2006;31:623-629.

12. Allison DB, Gomez JE, Heshka S, et al. Decreased resting metabolic rate among persons with Down syndrome. Int J Obes Relat Metab Disord 1995; 19:858-861.

13. Trazzi S, Mitrugno VM, Valli E, et al. APP-dependent up-regulation of Ptch1 underlies proliferation impairment of neural precursors in Down syndrome. Hum Mol Genet 2011:20:1560-1573.

14. Contestabile A, Fila T, Cappellini A, et al. Widespread impairment of cell proliferation in the neonate Ts65Dn mouse, a model for Down syndrome. Cell Prolif 2009;42:171-181.

15. de Arruda Cardoso Smith $\mathrm{M}$, Borsatto-Galera $\mathrm{B}$, Feller $\mathrm{Rl}$, et al. Telomeres on chromosome 21 and aging in lymphocytes and gingival fibroblasts from individuals with Down syndrome. J Oral Sci 2004:46:171-177.

16. Segal DJ, McCoy EE. Studies on Down's syndrome in tissue culture. I. Growth rates and protein contents of fibroblast cultures. J Cell Physiol 1974;83:85-90.

17. de Haan JB, Cristiano $F$, lannello $R$, et al. Elevation in the ratio of $\mathrm{Cu} / \mathrm{Zn}$-superoxide dismutase to glutathione peroxidase activity induces features of cellular senescence and this effect is mediated by hydrogen peroxide. Hum Mol Genet 1996;5:283-292.

18. Davisson MT, Schmidt C, Reeves $\mathrm{RH}$, et al. Segmental trisomy as a mouse model for Down syndrome. Prog Clin Biol Res 1993;384: 117-133.

19. Reeves R. A mouse model for Down syndrome exhibits learning and behaviour deficits. Nat Genet 1995;11:177-184.
20. Liu DP, Schmidt C, Billings T, et al. Quantitative PCR genotyping assay for the Ts65Dn mouse model of Down syndrome. Biotechniques 2003:35:1170-1174, 1176, 1178.

21. Nowakowski RS, Lewin SB, Miller MW. Bromodeoxyuridine immunohistochemical determination of the lengths of the cell cycle and the DNA-synthetic phase for an anatomically defined population. J Neurocytol 1989;18:311-318.

22. Hughes PC, Tanner JM. A longitudinal study of the growth of the black-hooded rat: methods of measurement and rates of growth for skull, limbs, pelvis, nose-rump and tail lengths. J Anat 1970;106:349-370.

23. Roper St RJ, John HK, Philip J, et al. Perinatal loss of TS65DN 'Down syndrome' mice. Genetics 2006;172:437-443.

24. Alonso L, Fuchs E. Stem cells of the skin epithelium. Proc Natl Acad Sci USA 2003;100(Suppl 1):11830-11835.

25. Soonpaa MH, Kim KK, Pajak L, et al. Cardiomyocyte DNA synthesis and binucleation during murine development. Am J Physiol 1996;271: H2183-H2189.

26. Kung JW, Currie IS, Forbes SJ, et al. Liver development, regeneration, and carcinogenesis. J Biomed Biotechnol 2010;26 (Article ID 984248; doi:10.1155/2010/984248).

27. Hermos JA, Mathan M, Trier JS. DNA synthesis and proliferation by villous epithelial cells in fetal rats. J Cell Biol 1971;50:255-258.

28. de Santa Barbara P, van den Brink GR, Roberts DJ. Development and differentiation of the intestinal epithelium. Cell Mol Life Sci 2003;60: 1322-1332.

29. Bach SP, Renehan AG, Potten CS. Stem cells: the intestinal stem cell as a paradigm. Carcinogenesis 2000;21:469-476.

30. Potten C, Wilson J. Development of epitjelial stem cell concepts. In: Lanza RP (ed). Handbook of Stem Cells, 2006.

31. Chang M, Parker EA, Muller TJ, et al. Changes in cell-cycle kinetics responsible for limiting somatic growth in mice. Pediatr Res 2008;64: 240-245.

32. Contestabile A, Fila T, Bartesaghi $\mathrm{R}$, et al. Cell cycle elongation impairs proliferation of cerebellar granule cell precursors in the Ts65Dn mouse, an animal model for Down syndrome. Brain Pathol 2009;19: 224-237.

33. Williams $\mathrm{AD}$, Mjaatvedt $\mathrm{CH}$, Moore $\mathrm{CS}$. Characterization of the cardiac phenotype in neonatal Ts65Dn mice. Dev Dyn 2008;237:426-435.

34. Ruchelli ED, Uri A, Dimmick JE, et al. Severe perinatal liver disease and Down syndrome: an apparent relationship. Hum Pathol 1991;22: 1274-1280.

35. Yagihashi N, Watanabe $\mathrm{K}$, Yagihashi S. Transient abnormal myelopoiesis accompanied by hepatic fibrosis in two infants with Down syndrome. J Clin Pathol 1995;48:973-975.

36. Seeff LB, Levitsky J, Tillman PW, et al. Histopathology of the liver in Down's syndrome. Am J Dig Dis 1967;12:1102-1113.

37. Geuna S, Borrione P, Filogamo G. Postnatal histogenesis in the peripheral nervous system. Int J Dev Neurosci 2002;20:475-479.

38. Litingtung $Y$, Lei $L$, Westphal $H$, et al. Sonic hedgehog is essential to foregut development. Nat Genet 1998;20:58-61.

39. Hirose $Y$, Itoh T, Miyajima A. Hedgehog signal activation coordinates proliferation and differentiation of fetal liver progenitor cells. Exp Cell Res 2009;315:2648-2657.

40. Tsukui T, Capdevila J, Tamura K, et al. Multiple left-right asymmetry defects in Shh(-/-) mutant mice unveil a convergence of the Shh and retinoic acid pathways in the control of Lefty-1. Proc Natl Acad Sci USA 1999:96:11376-11381

41. Nanba D, Nakanishi Y, Hieda Y. Role of sonic hedgehog signaling in epithelial and mesenchymal development of hair follicles in an organ culture of embryonic mouse skin. Dev Growth Differ 2003;45:231-239.

42. Athar $\mathrm{M}$, Tang $\mathrm{X}$, Lee JL, et al. Hedgehog signalling in skin development and cancer. Exp Dermatol 2006;15:667-677.

43. Roper RJ, VanHorn JF, Cain CC, et al. A neural crest deficit in Down syndrome mice is associated with deficient mitotic response to sonic hedgehog. Mech Dev 2009;126:212-219. 